\title{
Effect of frying temperature on amount of oil uptake of potato French fries
}

\begin{abstract}
Fat uptake and characteristics crispy texture are main quality parameters of fried potato products such as the most popular French fries and potato crisps. They are formed during the frying conditions were taken under investigation. Quality of frying oils as well as fatty acid composition and degree of degradation affect fat uptake and texture of fried potato products such as French fries and potato crisps are discussed. The kind and quality of frying medium as well as frying parameters (temperature) influence fat uptake and texture of fried potato. Texture of products correlated with fat content and composition of frying medium. Higher frying temperature decrease hardness of French fries and potato crisps which exhibit more crispy and delicate texture in composition with products fried at lower temperature. In this research, the effect of frying temperature at temperatures $180^{\circ} \mathrm{C}$ and $160^{\circ} \mathrm{C}$ for less of oil uptake of French fries were studied. Results showed that temperature of frying $180^{\circ} \mathrm{C}$ had fatter uptake than $160^{\circ} \mathrm{C}$. By this respect the highest and lowest of oil uptake were $28 \%$ and $23 \%$ which related $180^{\circ} \mathrm{C}$ and $160^{\circ} \mathrm{C}$ frying temperature. Thermal conductivity coeffient were 750 and $500 \mathrm{w} / \mathrm{mc}$ for temperature $180^{\circ} \mathrm{C}$ and $160^{\circ} \mathrm{C}$ respectively, this difference were significant $(\mathrm{p}<0.05)$. Thickness of crust and oil were 1.5 and $3.1 \mathrm{~mm}$ for temperatures $160^{\circ} \mathrm{C}$ and $180^{\circ} \mathrm{C}$ respectively that were significant difference $(p<0.05)$. At last temperature of frying $160^{\circ} \mathrm{C}$ at 10 minute were recommended for low fat French fries potato production.
\end{abstract}

Keywords: oil uptake, temperature of frying, french fried potato
Volume I Issue | - 2015

\author{
Habib O Mirzaei,' Theodoris karapanthios,' \\ Hagar garoumi, ${ }^{2}$ Frank Farhadpour ${ }^{3}$ \\ 'Gorgan University of Agricultural Science and Natural \\ Resources, Iran \\ ${ }^{2}$ Islamic Azad University, Iran \\ ${ }^{3}$ Master of food science and technology, Greece
}

Correspondence: Habib O Mirzaei, Gorgan University of Agricultural Science and Natural Resources, Iran, Tel +306951396398,Email mirzaeihabib I@gmail.com

Received: May 19,2015 | Published: June 06, 2015

\section{Introduction}

Potato (solanum tuberesum) is a tetraploid plant which belongs to solanum species and solmaceace family. This crop with world production of 400million ton is the most important agricultural crop after wheat, corn, and rice. Deep fat frying is a dry cooking process which is mainly immersing food pieces in hot vegetable oil. During the frying process, physical, chemical and oraganoleptic properties of food changed, the main goal of deep fat frying is to maintain tenderized and crispy shapes. Oil content is one of the important quality attributes in fried products. ${ }^{1}$ Fried potato products with low fat content have a hard and unfavourable texture. On the other hand high oil consumption is not cost -effective. For manufacturers and consumers products with high oil content are high fatty acid and tasteless. Today consumers are eating food products with lower fat content. ${ }^{2}$ Oil absorption during deep fat frying is controlled by parameters including oil quality, frying temperature and time. Deep -fat frying is one of the oldest processes of food preparation which consists basically in immersion of food pieces in hot vegetable oil. The high temperture causes partial evaporation of the water, which moves away from the food and through the surrounding oil. ${ }^{3}$ Oil is absorbed by the food, replacing some of the lost water. Several procedures have been proposed to reduce the oil absorbed. Low frying temperture or excess loading the fryer can decrease the oil uptake. ${ }^{4}$ When the temperature of frying is high, it takes more time to have the favorable color and flavor in the product which leads to higher oil uptake. Since moisture removal during frying is a key factor for oil uptake of fried products, low temperture have significantly lower oil uptake than high temperature. ${ }^{5}$ The determination of the exact instant that frying oil must be replenished is a major concern for avoiding possible health risks. ${ }^{6}$ By considering this, we aimed at finding the best temperture of frying which can be processed into french fries with lower oil content.

\section{Material and methods}

\section{Sample preparation}

Potatoes were supplied from local market of Greece. After peeling with an abrasive peeler, samples were converted to pieces two shapes with diameter $5 \mathrm{~cm}$ and thickness $1 \mathrm{~cm}$. Other shapes were $1 \mathrm{~cm}$ (length) $0.5 \mathrm{~cm}$ wide and $0.5 \mathrm{~cm}$ thickness. Samples were fried at two tempertures $180^{\circ} \mathrm{C}$ and $160^{\circ} \mathrm{C}$ for 10 minute. In order to curve weight of potato and temperture of oil with time of frying and conductivity coeffient and thickness of crust and oil uptake percent were measured. ${ }^{7,8}$

\section{i. Fryer model HD6103 philips}

ii. Sunflower oil was prepared from local market of Greece.

iii. Statistical analysis was compared using the Duncan test at 5\% significant level using with SAS soft ware.

\section{Thermal conductivity coefficient determination}

\section{Sample preparation}

The crust is withdrawn from French fries with a razor. The crust is stick on a Teflon disk. The disk is 3millimeter thickness, and 2 centimeter diameter. 


\section{Method}

The thermal conductivity coefficient is determined with the cool/ hot tank method. The sample of French fries is put between two tanks. The two tanks are filled with water, one with hot water, which is around $50^{\circ} \mathrm{C}$, the other with cool water, around $25^{\circ} \mathrm{C}$. Magnet inside the tanks and magnetic agitator secure the homogeneity of the temperature in each tanks. An insolation system protects the tanks from outside variation. Thermocouples measure the temperature in the two tanks during the experiment. The experiments run during 1000 second. The calculation of the heat flux transferred between those two tanks permit to determine the thermal conductivity coefficient of the sample.

\section{Thickness of crust measurement}

\section{Sample preparation}

The crust is withdrawn from French fries with a razor. Then, the crust is put on micro slides, for microscope analysis.

\section{Method}

A digital camera is put on a microscope. The samples are put in the microscope, with different zoom and lightness. The zoom available are $5 \mathrm{x}, 10 \mathrm{x}, 40 \mathrm{x}$ and 100x.

\section{Results and discussion}

Our results revealed that temperture of frying at $180^{\circ} \mathrm{C}$ had more oil uptake than temperture temperature of $160^{\circ} \mathrm{C}$. As it can be seen in Figure 1, potato weight (gm) were increased with increase of frying times, at time of frying (10 minute) potato weight of potato were reached minimum. For two size of potato, weight loss $\%$ were $64 \%$ and $58 \%$ for frying temperture of $180^{\circ} \mathrm{C}$ and $160^{\circ} \mathrm{C}$ respectively with significant deference $(\mathrm{p}<0.05) .{ }^{9}$ Similar results were obtained at frying temperture $160^{\circ} \mathrm{C}$ and $170^{\circ} \mathrm{C}$. On the other hand, loss of water is expected for two temperture but result of other researchers was for other variety of potato and less time of frying. This result was significant $(p<0.05)$. In Figure 2, temperture of oil at first decreased untill 3 minute of frying and increased from 3 to 10 minute for two tempertures 180 and $160^{\circ} \mathrm{C}$, but were more at $180^{\circ} \mathrm{C}$. This difference were non significant $(p>0.05)$. Our result showed that temperture of oil was higher $180^{\circ} \mathrm{C}$ than $160^{\circ} \mathrm{C}$ of frying. Thus oil uptake was higher at temperture of $180^{\circ} \mathrm{C}(\mathrm{p}<0.05)$. Considering crust evaluation, temperture of $180^{\circ} \mathrm{C}$ were related the highest thickness at 10 minute of thickness were 1.5 and $3.1 \mathrm{~mm}$ for $160^{\circ} \mathrm{C}$ and $180^{\circ} \mathrm{C}$ respectively this diferent were significant (Figure 3). Although thickness of crust was higher at $180^{\circ} \mathrm{C}$ but at $160^{\circ} \mathrm{C}$ was enough. Thermal conductivity coeffient were 750 and $500 \mathrm{wat} / \mathrm{mc}$ for $180^{\circ} \mathrm{C}$ and $160^{\circ} \mathrm{C}$ respectively, which were significant (Figure 4). At last, we resulted the best temperture of frying were $160^{\circ} \mathrm{C}$ for 10 minute for production of law fat French fries potato. Oil uptake \% were $28 \%$ and $23 \%$ for $180^{\circ} \mathrm{C}$ and $160^{\circ} \mathrm{C}$ respectively $(\mathrm{p}<0.05)$ (Figure 5).

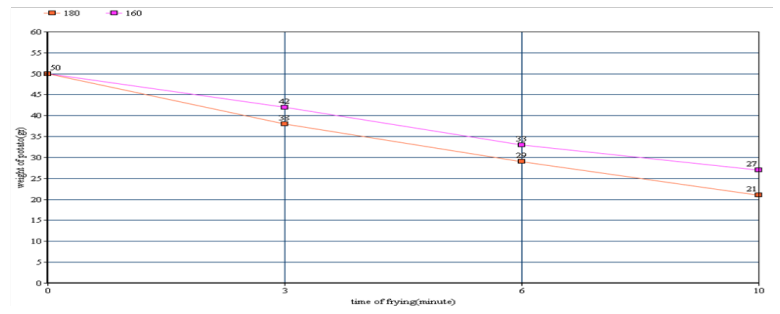

Figure I Some properties of French fries potato.

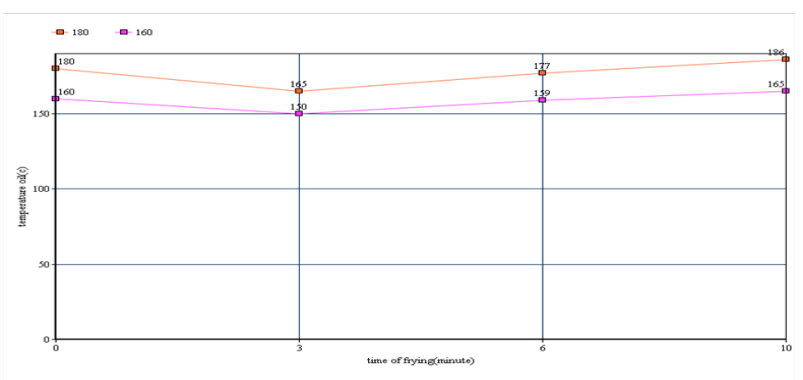

Figure 2 Some properties of French fries potato.

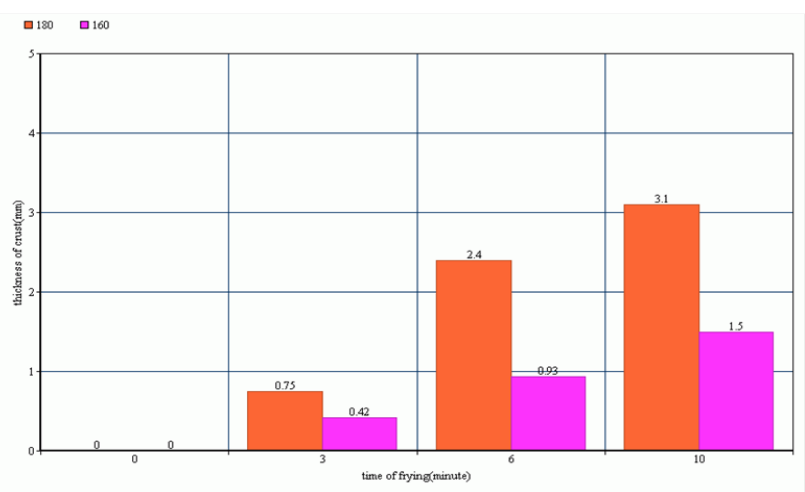

Figure 3 Some properties of French fries potato.

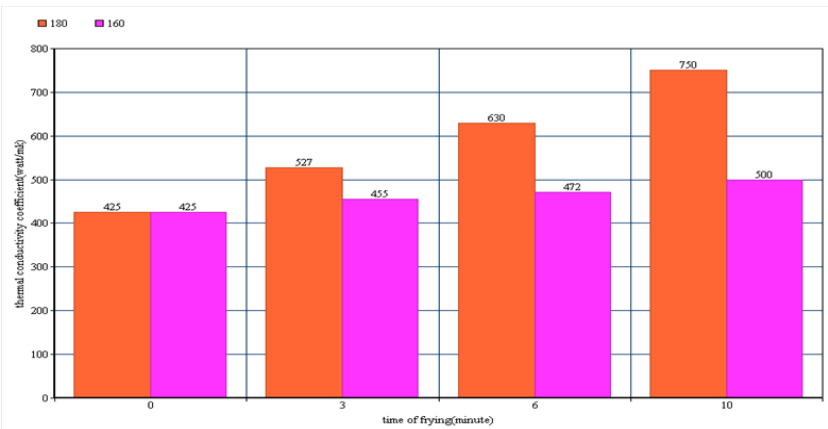

Figure 4 Some properties of French fries.

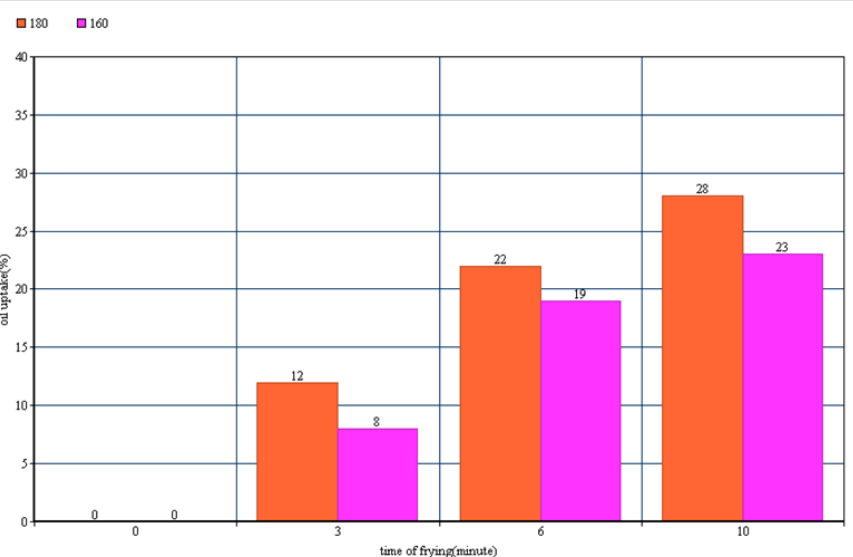

Figure 5 Some properties of French fries. 


\section{Conclusion}

Our results showed that since moisture removal during frying is a key factor for oil uptake. Considering temperture of $180^{\circ} \mathrm{C}$ was more oil absorption than temperture of $160^{\circ} \mathrm{C}$. But we were recommended $160^{\circ} \mathrm{C}$ frying temperture because had suitable texture, although temperture $180^{\circ} \mathrm{C}$ had high thickness of crust but contain high fat uptake $\%$. Thus temperture of $160^{\circ} \mathrm{C}$ were better because low of oil uptake and enough thickness of crust.

\section{Acknowledgements}

None.

\section{Conflict of interest}

The author declares no conflict of interest.

\section{References}

1. Agnieszka K. The effect of frying on fat uptake and texture of fried potato products. European Journal of Lipid science \& Technology. 2014;116(6):735-740.

2. Aminlari M, Ramezani R, Khalili MH. Production of protein -coated low fat potato chips. J Food Science Technol Int. 2005;11:177-181.
3. Dana D, Saguy IS. Mechanism of oil uptake during deep-fat frying and the surfactant effect-theory and myth. Adv Colloid Interface Sci. 2006;128130:267-272.

4. Khalil AH. Quality of french fried potatoes as influenced by coating with hydrocolloids. Food Chemistry. 1999;66(2):201-206.

5. Yadav DN, Rajan A. Fibers as an additives for oil reduction in deep fat fried poori. J Food Sci Technol. 2012;49(6):767-773.

6. Bouchon P, Aguilera JM, Pyle DL. Structure oil absorption relationships during deep fat frying. Journal of Food Science. 2003;68(9):2711-2716.

7. Pinthus EJ, Weinberg P. Deep-fat frying potato, oil uptake as affected by crust physical properties. J Food Science. 1995;60(4):250-262.

8. Garmakhany AD, Mirzaei OH, Nejad MK, et al. Study of oil uptake of potato chips. European Journal of Lipid Science \& Technology. 2008;110(11):1045-1049.

9. Lioumbas JS, Zamanis A, Karapantsios D. Towards a wicking rapid test for rejection assessment of reused fried oils: Results and analysis for extra virgin olive oil. Journal of Food engineering. 2013;119(2):260-270. 